$\mathrm{O}$ ne might think that after nearly a century of its flagship meetings, IUPAC's 42nd World Chemistry Congress and its 45th General Assembly would be little different than the previous gatherings. As it turned out, these IUPAC meetings, which took place in late July and early August 2011 in San Juan, Puerto Rico, were the first of their kind in many respects: the first to be held in a Latin American country, the first presided over by a woman president, and the first to be part of an International Year of Chemistry. The Congress itself was the first to feature seven

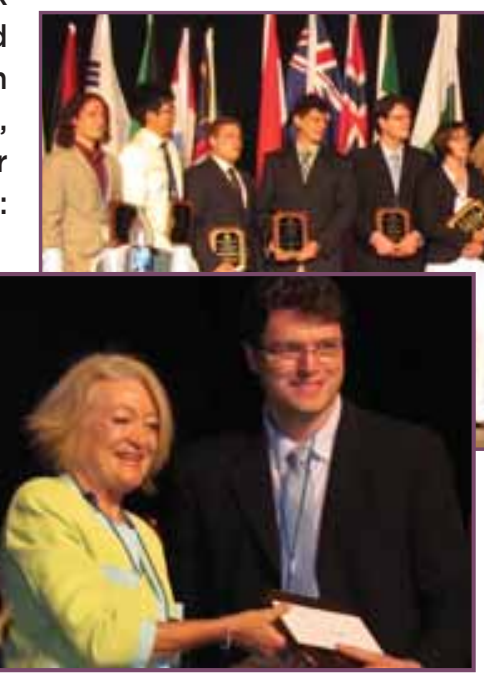

Nobel laureates in chemistry, this was the first GA at which social media was a source of news and information, and this was the first GA at which Richard Hartshorn arrived with his luggage.

Aside from the many "firsts" they offered, this IUPAC Congress and GA also felt different and not simply because of the island's pleasant tropical climate. The special energy, or "vibe," among attendees was likely due to the many activities and discussions involving the International Year of Chemistry. Among the most noteworthy IYC-related events were a day-long symposium devoted to women in chemistry, a huge chemistry festival held in Old San Juan, the World Chemistry Leadership Meeting, a special presentation of the Homo Sapiens Report by Michael Wadleigh, winner of the 1970 Academy Award for Best Documentary Feature for his documentary Woodstock, and an IYC booth for the Water globalXperiment held as part of the Congress Exhibit.
Aside from the excitement involving IYC 2011, the major news from the General Assembly was the election of Mark Cesa (USA) as vice president and the election of René Deplanque (Germany) as Secretary General. In addition, Javier García-Martínez (Spain)

\section{and Christopher Brett} (Portugal) were elected to the IUPAC Bureau for the first time. Ram Lamba (Puerto Rico) and Natalia Tarasova (Russia) were both reelected to the Bureau for their second fouryear terms.

The General Front: IUPAC President Nicole Assembly began 29 Moreau with Young Prize Winner William Donald. Back: 2010 and 2011 Winners of the IUPAC Prize for Young Chemists.

July with multiple meetings of the divisions and standing committees; the core business of the Union, and ended with the formal Council Meeting. At this GA, there were 517 registrants from 52 National Adhering Organizations, plus observers from Botswana, Peru, Colombia, and the Philippines.

President Nicole Moreau welcomed IUPAC members to the General Assembly and Congress at a well-attended and elaborate opening ceremony and reception. Eleven winners of the 2010 and 2011 IUPAC Prize for Young Chemists were presented during the Congress opening ceremony.

- Rubén Costa Riquelme, University of Valencia, Spain

- William Donald, University of California, Berkeley, California, USA

- Matthew Macauley, Simon Fraser University, Burnaby, British Columbia, Canada

- Bozhi Tian, Harvard University, Cambridge, Massachusetts, USA

- Sheng Xu, Georgia Institute of Technology, Atlanta, Georgia, USA

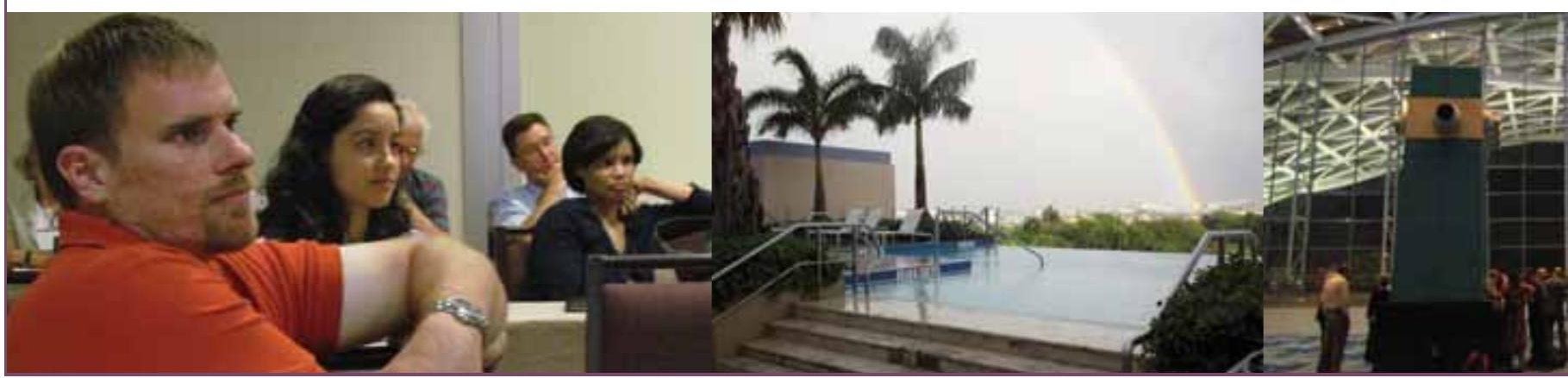



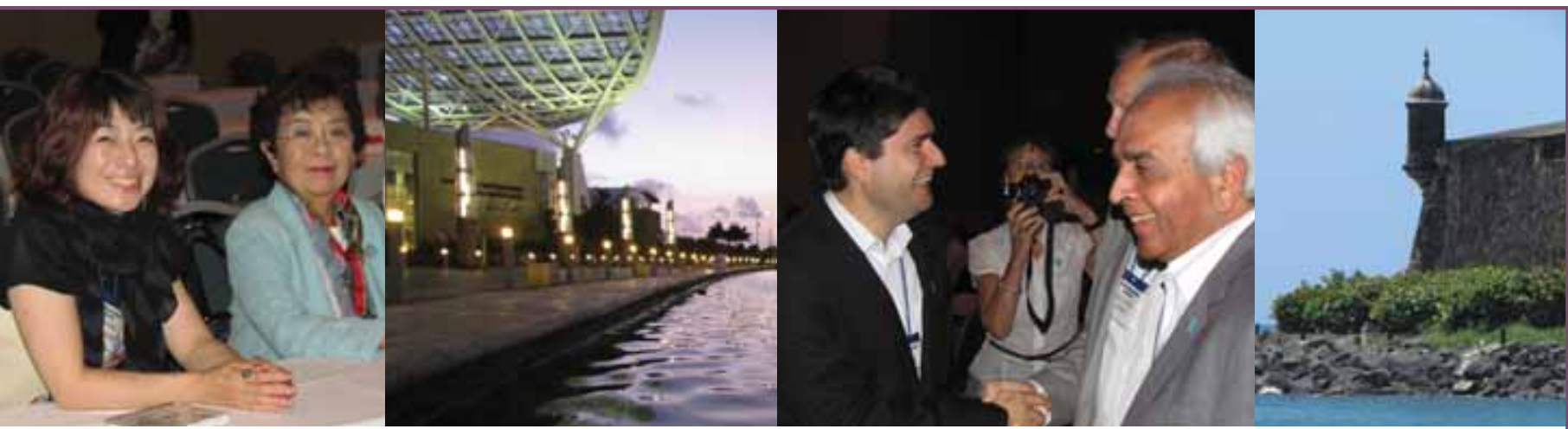

- Chengqi Yi, University of Chicago, Chicago, Illinois, USA

The winners of the 2010 IUPAC Prizes for Young Chemists are as follows:

- Guangbin Dong, Stanford University, Palo Alto, California, USA

- Viktoria Gessner, Technical University Dortmund, Dortmund, Germany

- Rafal Klajn, Northwestern University, Evanston, Illinois, USA

- Jason Spruell, Northwestern University, Evanston, Illinois, USA

- Guihua Yu, Harvard University, Cambridge, Massachusetts, USA

The essays describing the winners' theses can be found on the IUPAC website. A review article of their research is published in the IUPAC journal Pure and Applied Chemistry. (The 2010 prizes are published in PAC 2010, issue 12; 2011 prizes are expected for later this year.)

In spite of the threat from a tropical storm off of the coast of Puerto Rico, the Council meeting took place as scheduled on 3 and 4 August.

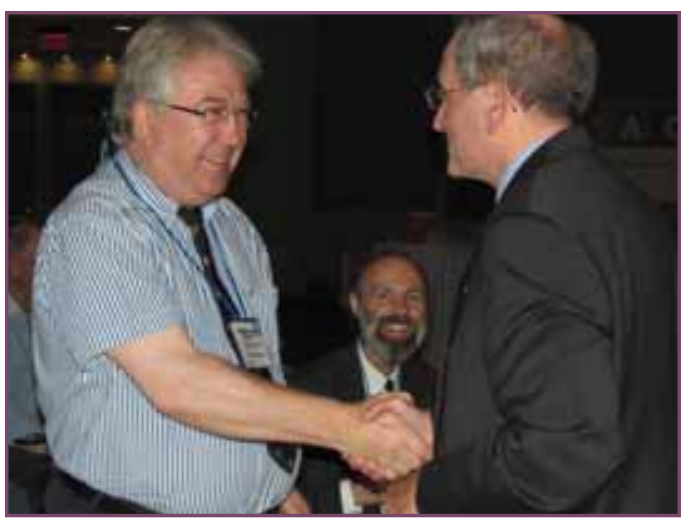

René Deplanque (left) and Mark Cesa congratulate eachother on their election wins.

Deplanque (Germany) will be the next secretary general and Cesa (USA) will become the next vice president.

delivered her President's State of the Union address, highlighting the fact that this was an especially busy year for IUPAC due to the concurrent International Year of Chemistry 2011. Her update of the IYC 2011 indicated that all cornerstone activities had been very successful to date. Next, Kazuyuki Tatsumi presented his Vice President's Critical Assessment. He stressed the importance of increasing IUPAC's global visibility and discussed growth objectives as the Union moves toward the 100th anniversary of its founding in 2019. David Black also delivered the Secretary General's report and expressed his thanks to the Council for its support during his eightyear tenure.

Three NAOs were formally welcomed to the IUPAC family by the vote of the Council Delegates. These were the Pancyprian Union of Chemists (Cyprus), the Tanzania Chemical Society (Tanzania), and the Chemical Society of Nigeria (Nigeria). With the addition of these three new members the total number of NAOs has increased to 58. In addition, the Indonesian Chemical Society (Indonesia) was approved by Council as an Associate National Adhering Organization (ANAO), President Moreau welcomed the Council delegates and observers and finalized the agenda. Former IUPAC President Bryan Henry, representing ICSU, also delivered a welcoming address. Thereafter, Moreau

bringing the total number of ANAOs to three. In addition, the Republic of Korea petitioned that its NAO Representative to IUPAC be changed from the Korean Federation of Science and Technology Societies to the

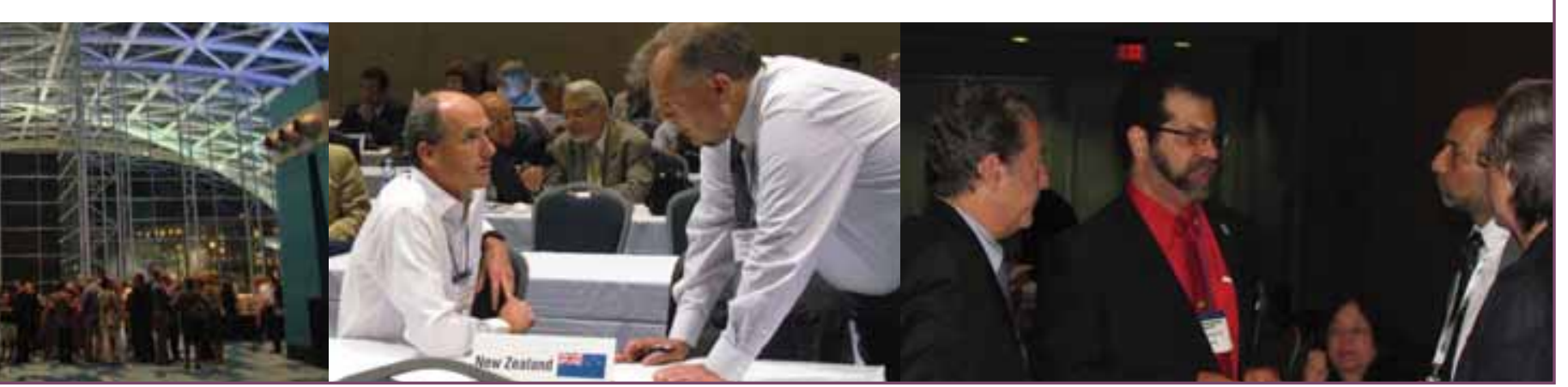




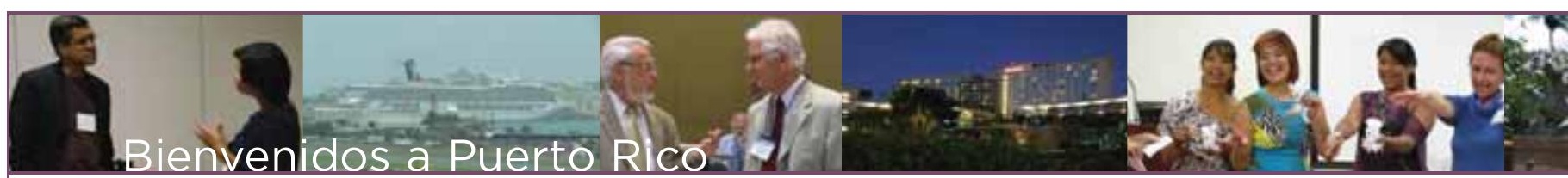

Korean Chemical Society. Brazil also petitioned that its NAO Representative be changed from the Brazilian Chemistry Committee for IUPAC to the Brazilian Chemical Society. Both petitions were approved unanimously by the Council.

Next on the Council docket were biennial reports of the divisions and standing committees, which were presented by the respective presidents and chairs and then opened for discussion and questions. (See the next $\mathrm{Cl}$ for echoes from the committee meetings at the GA.)

On the financial side, Treasurer John Corish delivered the Biennial Report of the Treasurer and the Report of the Finance Committee. Overall, the finances of the Union are stable, even in light of the worldwide economic decline in the past few years. In his Interim Report on IYC 2011 he noted that the level of financial sponsorship generated from sources external to IUPAC has been quite high and perhaps somewhat better than was initially expected. The full financial impact of IYC 2011 will not be known in detail until the close of the year. Corish also presented the new Biennial Budget and

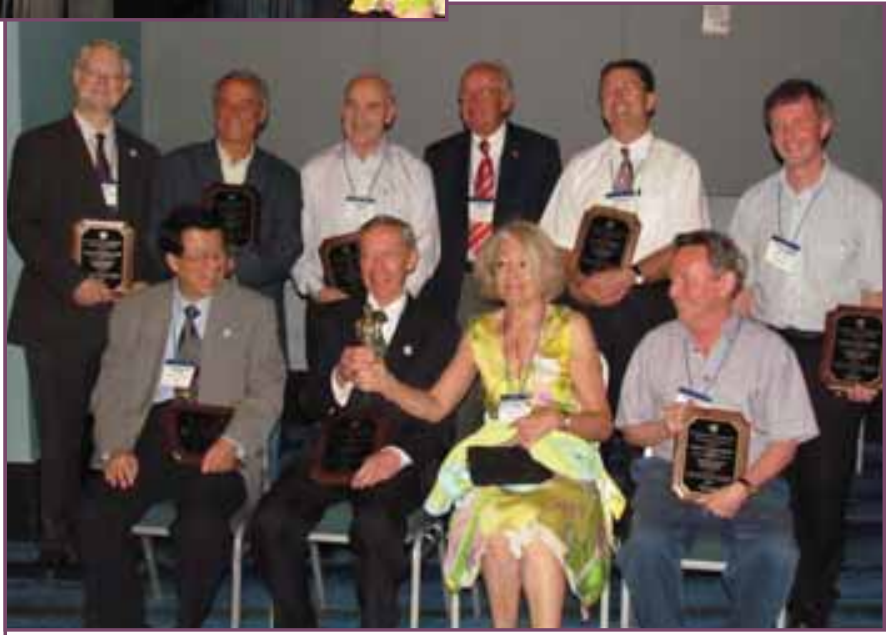

IUPAC's retiring officers, division presidents, and standing committee chairs pose with IUPAC President Nicole Moreau who is holding Michael Wadleigh's Oscar with Secretary General David StC. Black, part of an elaborate joke during the Recognition of Service ceremony. (IUPACers can puzzle the caption and recognize that standing on the back raw, from left to right is DP4, DP6, $D P 1, D P 3, D P 5, C C E C$, and sitting is $P P, S G, P$, and $D P 7)$.
National Subscriptions for 2012-2013. The Council approved both the new Budget and the National Subscription schedule as proposed.

Applications for two new Associated Organizations were approved by the Council: the European Chemistry Thematic Network Association and the Federation of Asian Polymer Societies.

The Turkish delegation reported on preparations for the 47th General Assembly and 44th World Chemistry Congress to be held in Istanbul in 2013. Preparations are well in hand for another successful biennial event. See <www.iupac2013.org> for updates. There was no update about the 2015 Congress which is to be held in Korea.

Colin Humphris addressed the Council with a summary of the World Chemistry Leadership Meeting (WCLM), which took place the day prior to the Council meeting. In this key activity of the IYC 2011, stakeholders gathered to debate the issues of sustainable development and how chemists led by IUPAC could make a positive impact by helping to solve the global problems of clean water, human health, agriculture and food production, and renewable energy supply through green chemistry. A highlight of the full-day event was a screening of the Future of Sustainable Chemistry <www.futurewecreate.com>, a video project and virtual conference hosted by The Dow Chemical Company, a major sponsor of the WCLM. A full recap of the WCLM will appear in the January issue.

\section{Recognition of Service}

There is no formal training that can prepare someone to become a good leader in an organization such as IUPAC. Division presidents and standing committee chairs can attest that their jobs are frequently challenging. One of Piet Steyn's priorities when he was IUPAC president (2002-2003) was to recognize the achievements of chemists and members of IUPAC. In 2003, he instituted a formal ceremony to honor and recognize the service of IUPAC's retiring officers, division presidents, and standing committee chairs. The tradition has continued since and at the conclusion of the President's Address on 30 July, IUPAC President Nicole Moreau presented plaques to the following members:

- Jim McQuillan retiring as president of the Physical and Biophysical Chemistry Division (DP1)

- $\quad$ Gerrit Koomen retiring as president of the Organic and Biomolecular Chemistry Division (DP3)

- Chris Ober retiring as president of the Polymer Division (DP4) 
- $\quad$ Ales Fajgelj retiring as president of the Analytical Chemistry Division (DP5)

- Nicola Senesi retiring as president of the Chemistry and the Environment Division (DP6)

- Doug Templeton retiring as president of the Chemistry and Human Health Division (DP7)

- Peter Mahaffy retiring as chair of the Committee on Chemistry Education (CCEC)

- David Black retiring as Secretary General (SG)

- Jung-II Jin retiring as vice president, president, and past president (PP)

\section{Young Observers}

"Any scientific discipline, if it plans to remain vibrant and innovative, must explore ways to renew itself as it expands into new areas and develops new techniques." These were the words of former IUPAC Bureau member E.P. Przybylowicz and he was referring to the Young Observers (YOs) program.

For nearly 15 years, Young Observers have participated in session of the General Assembly. These

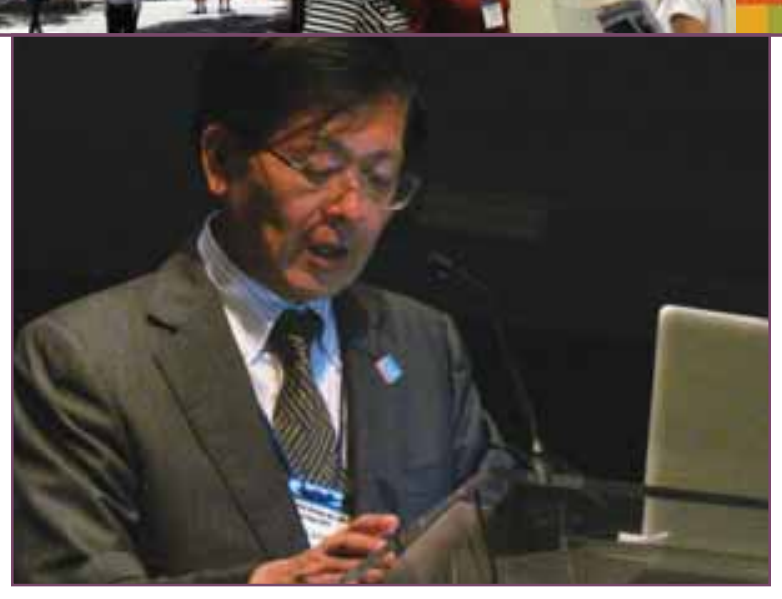

Kazuyuki Tatsumi (Japan) presenting his Vice President's Critical Assessment.

chemists, who represent a broad array of expertise and professional backgrounds, add vitality and a valuable perspective to the committee work in which they participate. This year, the IUPAC GA welcomed 19 YOs from 9 countries: China, India, Ireland, Japan, Peru, Philippines, Turkey, UK, and the USA.

The YOs briefing session on 28 July, in which some officers and members participated, provided an infor-

\section{From Swaziland to}

\section{San Juan}

One of the Young Observers at the GA shared a fascinating story about the role that IUPAC played in his decision to pursue a Ph.D. in chemistry. After obtaining a B.S. in chemistry as an undergrad, Justin Youngblood found himself unsure what to do with his degree. So, as many have done before, he joined the Peace Corps and found himself in Swaziland, the small country between South Africa and Mozambique.

At one point in 1996, Youngblood traveled by bus to Windhoek, Namibia, for a week-long break. The trip involved a long stopover in Johannesburg where he would catch a bus to take him across South Africa's Transvaal region (great plains). With the University of the Witwatersrand a short walk from the bus rank in downtown Johannesburg, Youngblood said that "curiosity got the better of me." Upon exploring the chemistry department, he came across a flyer for an IUPAC conference on chemistry and the environment that grabbed his attention.

A few months later, Youngblood returned to the campus to attend the conference and it proved to be a life-changing moment. The lectures were so fascinating that he decided then and there that he would eventually pursue a Ph.D. in chemistry. Further, he made a commitment to use chemistry to help the environment. Today, as a professor of chemistry at the University of North Texas, his research focuses on using synthetic organic chemistry to design compounds for studying and improving electron transport behavior in solar cells. And, all these years later, having come full circle in a sense, Prof. Youngblood confided that he still has a memento from that conference in Durban: the original flyer that reignited his passion for chemistry.
"IUPAC has been a great inspiration in my life and career," Youngblood said. "I hope in the future to give back in a way that helps IUPAC to inspire another generation of scientists to work on scientific topics that can benefit Earth and humanity."

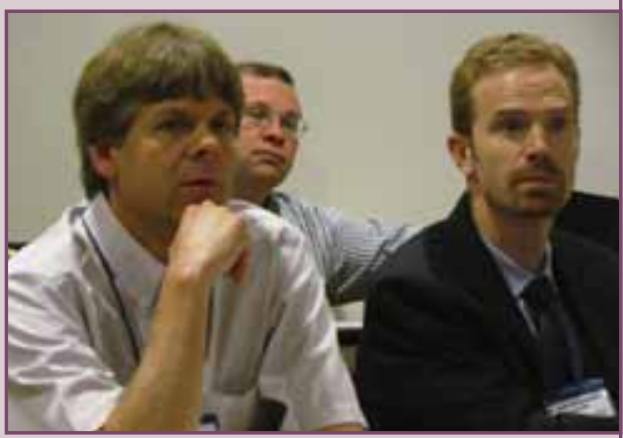

W. Justin Youngblood (University of North Texas, Denton, TX, USA) is seated to the right. Fellow Young Observer Leif Abrell (University of Arizona, Tuscon, $A Z, U S A$ ) is on the left, and former YO Daniel Rabinovich, University of North Carolina (USA), is in the back. 


\section{Bienvenidos a Puerto Rico}

mal introduction to IUPAC and gave YOs an idea of what to expect during committee meetings. The 2011 YOs are listed at http://2011ga.wordpress.com.

In fact, the 2011 YOs were the first, and perhaps the most active, participants in a social networking experiment that was conducted during the GA. Despite a lot of discussion about harnessing social networking tools, IUPAC had not yet ventured into this territory. Nevertheless, the $\mathrm{Cl}$ team of editors undertook an experiment to develop and maintain a presence on Facebook, Twitter, and a blog during the GA.

\section{Join the Experiment! GA stay informed • connect • share sanuan, PR}

\section{facebook}

....tinyurl.com/iupac2011ga

(1V) WordPress Blog • 2011ga.wordpress.com

Euilter........\#2011GenAssembly
These social tools were designed to provide news and resources for those attending the GA and to replace the former printed GA newsletter, GAllium which served three consecutive GAs starting in Beijing in 2005. It was hoped that this medium of communication would be more spontaneous and more inviting as everyone could make posts, add comments, share links, upload photos, and be part of the discussion. Finally for those unable to join the GA, it was a way for them to get the vibe of what was going on. Now that the GA is over, it is still a valuable reference.

As the GA took place and the experiment got underway, it was rewarding to be able to post news and updates in real time and have people react. The $\mathrm{Cl}$ team was pleased with the numbers, which gradually grew: by the end of the GA, the raw numbers for Facebook were around 7500 post views, 60 likes, and 195 active users. As Linus Pauling said: "The way to get good ideas is to get lots of ideas, and throw the bad ones away" ... with that in mind, the $\mathrm{Cl}$ team is now planning to develop a social network experience for $\mathrm{Cl}$.

\section{Learning with Laughter}

On 29 July 2011, 20 high school and middle school science teachers who might otherwise be enjoying their summer breaks, gathered for a workshop to learn how to implement the Young Ambassadors for Chemistry program in their classrooms. Since 2004, the Young Ambassadors for Chemistry has been an important project of the IUPAC Committee on Chemistry Education, with the ultimate goal of increasing public interest in chemistry (see IUPAC project 2007005-2-050 for more details). Held at the Chemistry Department of the University of Puerto Rico-Rio

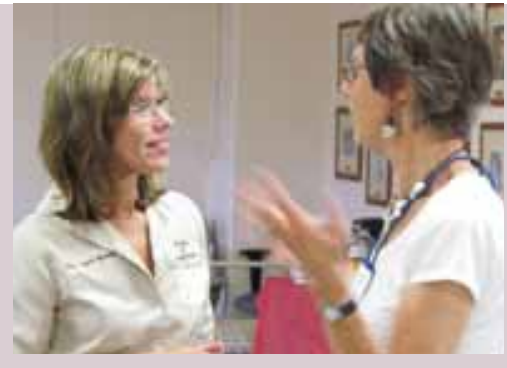

Ingrid Montes (left) and Lida Schoen.

Piedras in San Juan, the workshop found a highly receptive and enthusiastic audience. The teachers were guided through the workshop by Lida Schoen and Erica Steenberg, Science Across the World team members, who used a "train the teachers" approach in which the teachers perform the same experiments and exercises that they will have their students perform. Workshop participants were assisted by a friendly group of graduate students of Prof. Ingrid Montes of the Department of Chemistry.

As the photos below attest, the teachers at the workshop shared many laughs as they created and performed skits of television commercials for the creams and lotions they created in the earlier experiments.

www.chemistry2011.org/participate/ideas/

[iii) show?id=6

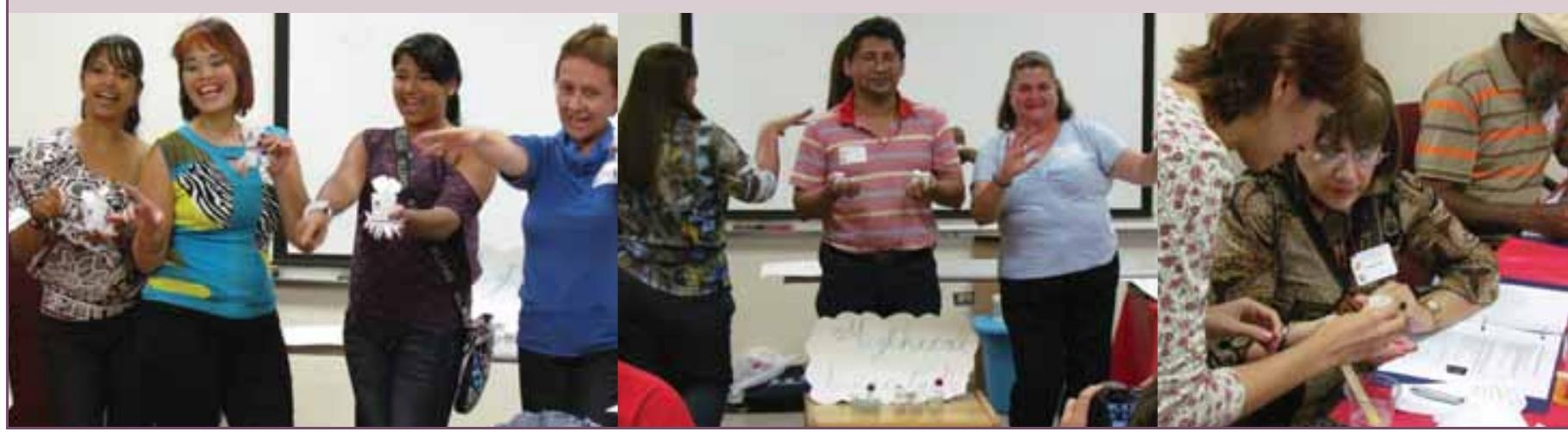

